\title{
Study of Serum Aspartate Aminotransferase, Alanine Transaminase, Alkaline Phosphatase in Burn Cases
}

\author{
Authors
Dr Mousumi Borgohain Borah ${ }^{1}$, Dr Malavika Barman ${ }^{1}$, Dr Mauchumi Saikia Pathak ${ }^{2}$, Dr Rashmi Rasi Datta ${ }^{3}$ \\ ${ }^{1}$ Assistant Professor, Department of Biochemistry, Gauhati Medical College \& Hospital, Guwahati \\ ${ }^{2}$ Professor and HOD, Department of Biochemistry, Tezpur Medical College \& Hospital, Bihaguri, Tezpur \\ ${ }^{3}$ Manager - Autochemistry and Special Chemistry, Quest Diagnostics, India
}

Corresponding Author

Dr Malavika Barman

Assistant Professor, Department of Biochemistry, Gauhati Medical College \& Hospital, Guwahati India

\begin{abstract}
Introduction: Burn is injury of flesh that represents one of the most severe forms of trauma caused by heat, electricity, chemicals, light and radiation. Most burns affect only the skin, rarely deeper tissues, such as muscles, bone and blood vessels. A severe burn represents a devastating injury affecting nearly every body organ system and leads to significant patient morbidity and mortality.

Aims and Objectives: The current study on liver enzymes serum aspartate aminotransferase, alanine transaminase, alkaline phosphatase in burn patients was under taken to access and correlate the liver enzymes to the degree of burn injury

Materials and Methods: The study involved 60 hospitalized patients with burn injury irrespective of sex and age between 20-50 years admitted at Gauhati Medical College \& hospital between July 2014 to August 2015. Estimation of AST, ALT, ALKP was done in Vitros 5600 by the slide method.

Results and Observations: In the present study, we found that the liver enzymes, AST,ALT,ALKP were significantly elevated between 5-10 days in the study group as compared with control group $(<0.05)$. Significant variation in the rise of liver enzymes is also seen with different degrees of burn.

Discussion: There is strong association and positive correlation between liver enzymes and degree of burns. The cause of increase rise of liver enzymes AST,ALT,ALKP is due to liver cell damage. Restoration of liver function will improve morbidity and mortality of severely burned patients.

Keywords: Burn, Liver enzymes, AST,ALT,ALKP.
\end{abstract}

\section{Introduction}

WHO has defined Burn as "an injury to the skin or other organic tissue primarily caused by heat or due to radiation, radioactivity, electricity, friction or contact with chemicals. ${ }^{1}$ Thermal (heat) burns occur when some or all of the cells in the skin or other tissues are destroyed by:
- hot liquids (scalds)

- hot solids (contact burns), or

- flames (flame burns)"

Superficial burn (formally referred as first degree burns) injure only the epidermis. It does not damage the dermal epidermal junction. Second degree burn are now commonly referred to as 
either superficial or deep partial thickness burns .Superficial partial thickness burn extend through the dermis into the papillary dermis, injury the pain sensitive nerve endings. Deep partial thickness burn extends through the epidermis and damage both the papillary and reticular dermis. Full thickness burns (formally referred as third degree burns) involve all the layers of the epidermis and dermis and may extend into the subcutaneous structure.

Burns are a global public health problem, accounting for an estimated 265000 deaths annually and over $96 \%$ of fatal fire-related burns occur in low- and middle-income countries ${ }^{1}$.

A severe burn represents a devastating injury affecting nearly every body organ system and leads to significant patient morbidity and mortality, prolonged hospitalisation, disability and disfigurement often with resulting stigma and rejection. In India, over 10,00,000 people are moderately or severely burnt every year. ${ }^{2,3}$

Previous studies show that Burn produces a profound hypermetabolic stress response which in turn causes inflammatory response. When there is sustained or increased hypermetabolic, inflammatory responses it can be life threatening. ${ }^{4,5}$ Burns have significant impact on the metabolic function of the liver. ${ }^{6,7}$ After a thermal injury, a variable degree of liver injury is present usually related to the severity of the thermal injury. ${ }^{8,9}$

There is strong evidence that the liver undergoes hypertrophy after burn. ${ }^{10,11}$ The extent and duration of liver enlargement and the associated functional changes, however, are not known. Liver plays a pivotal role in patient survival and recovery by modulating multiple pathways. ${ }^{12}$ The aim of this study was to assess the liver enzymes in cases of burn injuries, correlate liver enzymes with extent and depth of burn injury and thirdly to utilize data for a new clinical approach for better management of burn patients.

\section{Materials and Methods}

The study involved 60 hospitalized patients with burn injury irrespective of sex and age between
20-50 years. Serum samples were collected between 5 to 10 days after burn. The values of AST, ALT, ALKP of 60 burn cases admitted at Gauhati Medical College was assayed in Vitros 5600 Analyser of Ortho Clinical Laboratories by the slide method. The study was carried out between July 2014 to August 2015. Patients having history of chronic alcohol intake, liver disease, recent infection were excluded from the study.

Normal AST level is taken as 14-36 U/L , ALT level is taken as 9-52U/L and ALKP 38-126U/L when done in Vitros 5600

The test group was further Sub-divided into 3 groups on the basis of the percentage of burn injuries received as per the Rule of 9. ${ }^{13,14}$

Group-1 included patients with less than 35\% burn (mild injury)

Group-II included patients with $35-65 \%$ (Moderate Injury) Group-III included patients with $>65 \%$ burn (Severe Injury) 60 healthy age $\&$ sex matched control group.

\section{Results and Observations}

The liver enzymes AST, ALT and ALKP of 60 burn patients were estimated and were included in the study group after evaluation with the inclusion and exclusion criteria.

Fig: 1 Mean Serum AST Values of Control Group and Diff. Degrees of Burn

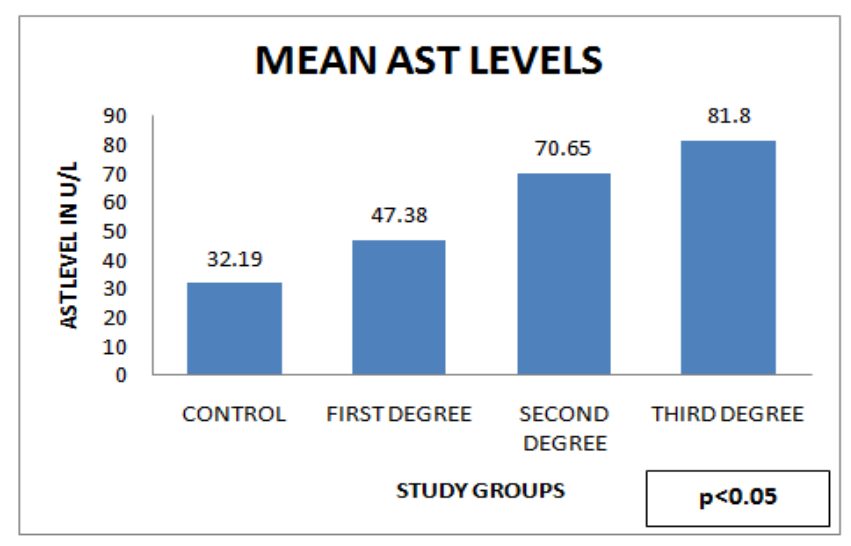


Fig: 2- Mean Serum AST Values of Control Group and Diff. Degrees of Burn

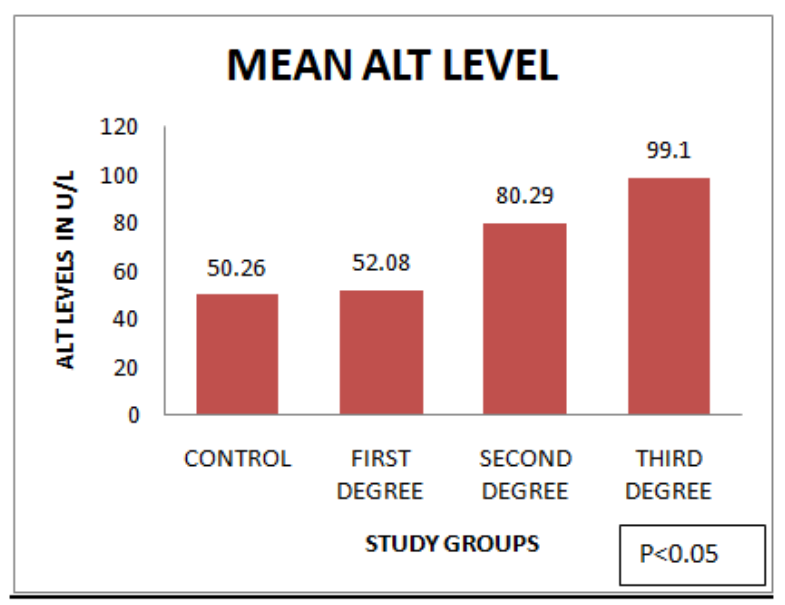

Fig: 3- Mean Serum ALKP Values of the Control Group and Diff. Degrees of Burn

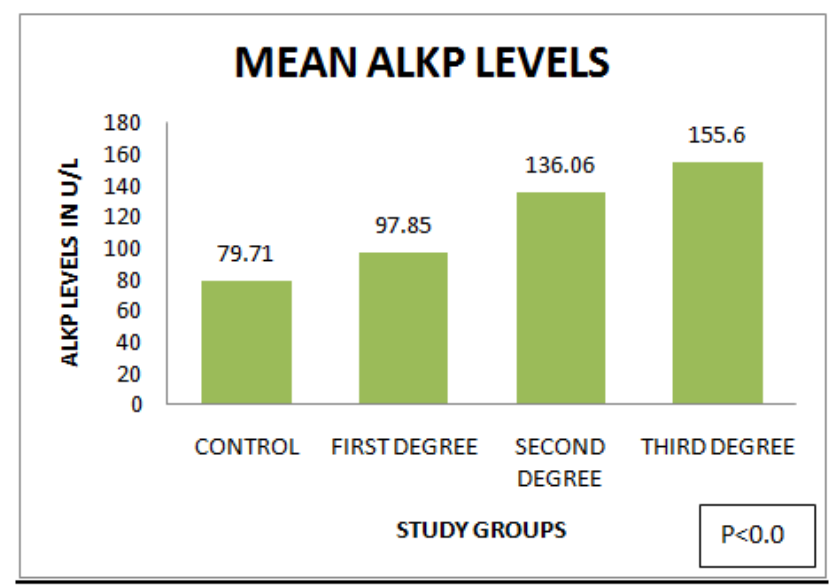

\section{Discussion}

Burn injury is accompanied by complex patho physiological process ${ }^{[13]}$. Autopsies of burned patient showed that fatty liver infiltration was associated with increased bacterial translocation, liver failure, and endotoxemia, thus showing the crucial role of the liver during the post burn response $\mathrm{e}^{[15,16]}$. Usually there is variable degree of liver injury is present related to the severity of burn.

In the present study, we found that the levels of the hepatic enzymes serum aspartate aminotransferase (AST), serum alanine aminotransferase (ALT), and ALKP were increased during the acute post burn phase. AST, ALT, ALKP were significantly elevated between 5-10 days in the study group as compared with control group $(<0.05)$. Significant variation in the rise of liver enzymes is also seen with different degrees of burn.

\section{Conclusion}

There is strong association and positive correlation between liver enzymes and degree of burns. Rise of liver enzymes immediately after burn may be due to hepatic edema formation, leading to cell damage with the release of hepatic enzymes.

Assessment of liver function is important for post burn outcome and we propose that attenuation of liver damage and restoration of liver function will improve morbidity and mortality of severely burned patients.

\section{References}

1. Burns". World Health Organization. September 2016. Archived from the original on 21 July 2017. Retrieved 1 August 2017

2. "Burns Fact sheet N ${ }^{\circ} 365 "$. WHO. April 2014. Archived from the original on 201511-10. Retrieved 3 March 2016.

3. Herndon D, ed. (2012). "Chapter 4: Prevention of Burn Injuries". Total burn care (4th ed.). Edinburgh: Saunders. p. 46. ISBN 978-1-4377-2786-9

4. Herndon DN, Tompkins RG. (2004) Support of the metabolic response to burn injury. Lancet 363: 1895-1902

5. Van den Berge G, et al. (2001) Intensive insulin therapy in critically ill patients. New Engl.J Med 345: 1359-1367.

6. Linares HA (1988) Autopsy findings in burned children. In: Carvajal HF, Parks DH (eds) Burns in Children: Pediatric Burn Management. Year Book Medical Pub, Chicago.

7. Barret JP, Jeschke MG, Herndon DN: Fatty infiltration of the liver in severely burned pediatric patients: autopsy findings 
and clinical implications. $\mathrm{J}$ Trauma 51:736-739, 2001.

8. Fischer JE, Hasselgren PO: Cytokines and glucocorticoids in the regulation of the "hepato-skeletal muscle axis" in sepsis. Am J Surg 161:266-271, 1991.

9. Hiyama DT, von Allmen D, Rosenblum L, Ogle CK, Hasselgren PO, Fischer JE: Synthesis of albumin and acute-phase proteins in perfused liver after burn injury in rats. J Burn Care Rehabil 12:1-6, 1991.

10. Jeschke MG, Barrow RE, Herndon DN: Extended hypermetabolic response of the liver in severely burned pediatric patients. Arch Surg 139:641-647, 2004.

11. Barrow RE, Hawkins HK, Aarsland A, Cox R, Rosenblatt J, Barrow LN, Jeschke MG, Herndon DN: Identification of factors contributing to hepatomegaly in severely burned children. Shock 24:523-528, 2005

12. Moshage H. (1997) Cytokines and the hepatic acute phase response. J Pathol 181: 257-266.

13. Wallace, A.B. The Treatment of Burns. Lord Horder. Oxford University Press. 1941.

14. Garmel, edited by S.V. Mahadevan, Gus M. (2012). An introduction to clinical emergency medicine (2nd ed.). Cambridge: Cambridge University Press. pp. 216-219. ISBN 978-0-521-74776-9.

15. Mittendorfer B, Jeschke MG, Wolf SE, Sidossis LS: Nutritional hepatic steatosis and mortality after burn injury in rats. Clin Nutr 17:293-299, 1998.

16. Jeschke MG, Low JF, Spies M, Vita R, Hawkins HK, Herndon DN, Barrow RE: Cell proliferation, apoptosis, NF-kappaB expression, enzyme, protein, and weight changes in livers of burned rats. Am J Physiol Gastrointest Liver Physiol 280:G1314-G1320, 2001. 